\title{
ZINC ELECTROWINNING USING REACTIVE ELECTRODIALYSIS (RED)
} GERARDO CIFUENTES, PABLO BUSTOS, JOSÉ HERNÁNDEZ AND NICOLÁS GUAJARDO

\author{
Departament of Metallurgical Engineering, Faculty of Engineering, Universidad de Santiago de Chile, Avenida Libertador Bernardo O'Higgins 3363, \\ Casilla 10233, Telephone No.:56-2-27183224, Santiago, Chile.
}

\begin{abstract}
This paper presents an alternative process for the conventional zinc electrowinning, which consists of a cell of two compartments separated by a anion exchange membrane.One of them contains a zinc sulphate catholyte and sulfuric acid while the anolyte solution contains ferrous sulfate and sulfuric acid.By using a membrane the classical lead anode may be replaced, as well as the main oxidation reaction of water, for that of the ferrous ion to ferric ion.This leads to significant savings in specific energy consumption of the overall process and eliminates the classic problem of acid mist in electrowinning cells. The results show that the proposed process consumes $30 \%$ less cell potential compared to conventional electrowinning cell.
\end{abstract}

Keywords: zinc, electro-winning, reactive electrodialysis.

\section{INTRODUCTION}

The process of obtaining zinc from zinc sulfide ore consists of 4 stages, according to Figure 1.1: roasting, leaching, purification and electrolysis. ${ }^{1}$

Roasting involves the transformation of zinc sulfide into zinc oxide so that it can be readily leached with sulfuric acid. Once the zinc sulphate solution is obtained, the solution goes through purification for the removal of more noble metals, including: cadmium, copper, nickel and cobalt, since their presence would greatly affect the current efficiency of zinc electro-winning.

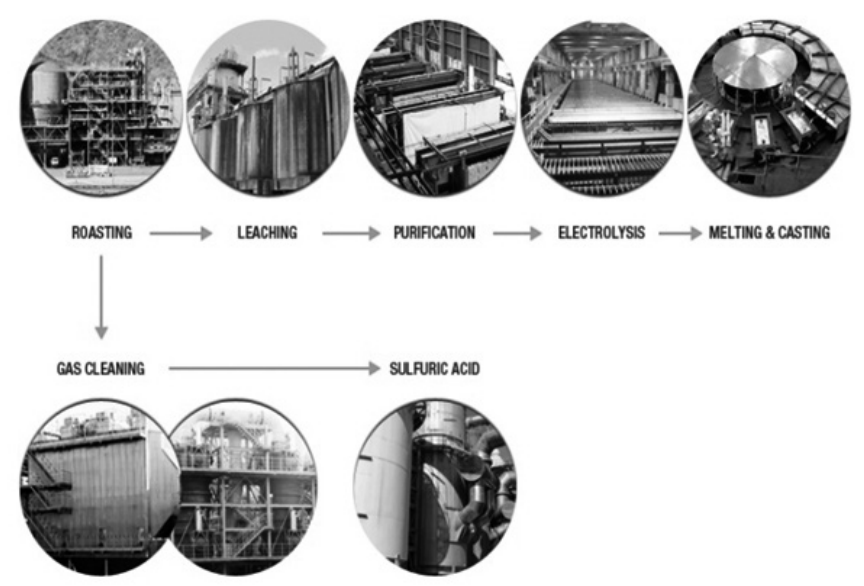

Figure 1.1.Schematic diagram of Zinc production. ${ }^{1}$

This process is performed using the electrochemical reactions of water oxidation on a lead anode $e^{2,3,4}$ and zinc reduction in a solution on an aluminum cathode. Within the zinc electro-winning process, in spite of having being used for several years, there are two major drawbacks: the first is the generation of acid mist produced by the $\mathrm{O}_{2}$ evolution reaction at the anode, which causes damage to the working plant. The second of these is the use of lead anodes. The latter is responsible for a significant fraction of the overall energy consumption of the cell, because it requires a great deal of energy to ensure the thermodynamic stability of the lead dioxide layer on its surface. In other words, the reaction:

$$
2 \mathrm{H}_{2} \mathrm{O}+\mathrm{PbSO}_{4}=\mathrm{PbO}_{2}+4 \mathrm{H}^{+}+\mathrm{SO}_{4}{ }^{2-}+2 e^{-}
$$
dioxide.

requires energy in order to be shifted towards de production of lead

If this energy is not supplied, lead sulfate is formed on the surface of the anode. This is an insulating species, and its formation would require the process to be stopped.In mathematical terms, these problems can be analyzed through equation $(1.1)^{5}$ :

$$
V_{c e l l}=\Delta E_{t h}+\mu_{a}+\mu_{c}+I \cdot R e
$$

Where $V_{c e l l}$ is the cell potential in the working cell, $\Delta E_{t h}$ is the equilib $\mu_{a} y \mu_{c}$ and are the anode and cathode overpotentials, and $I \cdot R e$ is the ohmic drop in potential in the electrolyte.

Electrodialysis systems purify solutions using ionic exchange membranes ${ }^{6,7,8,9,10,11}$. Implementing the cathodic or anionic membranes enables the use of different work environments for the same working cell ${ }^{12,13,14}$. In this case, the anolyte is a solution of ferrous sulfate and sulfuric acid.In this methodology of work, equation (1.1) should consider the potential drop in the membrane and in each electrolyte.Therefore, this equation will be replaced in this system by equation $(1.2)^{6}$ :

$$
V_{\text {cell }}=\Delta E_{\mathrm{th}}+\mu_{\mathrm{a}}+\mu_{c}+I \cdot\left(R_{a}+R_{c}+R_{m}\right)(1.2)
$$

Where $R_{a}, R_{c} y R_{m}$ and represent the resistances in the anolyte, the catholyte and the membrane, re $\Delta E \quad y$, ough the membrane adds to the drop in potential, the values of $\Delta E_{t h} y \mu_{a^{3}}$ and, decrease, as the acid fog in the work cell is also avoided. ${ }^{14}$ The objective of this article is to evaluate the operational parameters of the proposed work system and compare them with conventional electro-winning.

\section{EXPERIMENTAL}

The diagram in Figure 2.1 shows the system used for testing of Zinc electro-winning using the RED method.

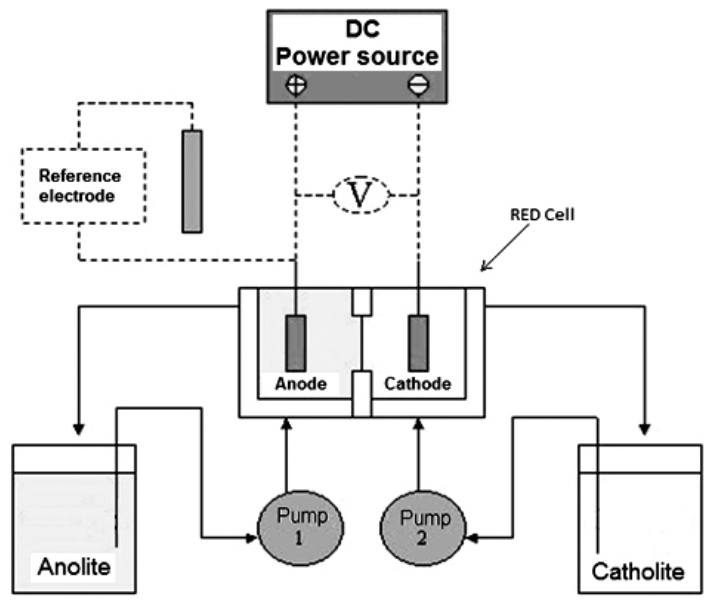

Figure 2.1.Work system for zinc electro-winning with RED method. 
Figure 2.1 shows the elements that compose the work system. In the electrodialysis cell (RED), the anolyte and the catholyte were separated through the use of a cationic membrane. Both solutions were stirred with a magnetic stirrer inside the cell, at a speed of $600 \mathrm{rpm}$. The composition of the anolyte was 0.5 $\mathrm{M}$ and $1 \mathrm{M}$ of sulfuric acid and ferrous sulfate, while the catholyte was $0.5 \mathrm{M}$ sulfuric acid and $1 \mathrm{M}$ zinc sulfate. A $2 \times 2 \mathrm{~cm}$ Ionac MA3475 anionic membrane was used as the separation medium between the two electrolyte compartments. The tests were carried out at temperatures between 25 and $50^{\circ} \mathrm{C}$. The electrodialysis cell is shown in Figure 2.2:

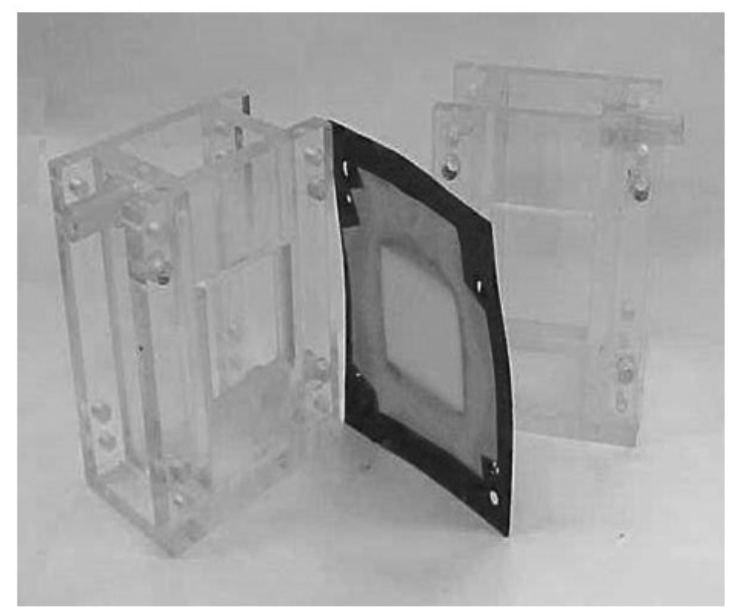

Figure 2.2.Used work cell and Ionac MA3475 anionic membrane.

The performance of every working electrode was evaluated using a potentiostat in the lineal voltammetry mode. This kind of test requires the use of 3 electrodes: working electrode, reference electrode (mercury sulfate electrode in this case, because this one does not react with the sulfate media) and the auxiliary electrode used to close the circuit. Finally, the influence of the stirring and the current intensity over the cell potential was evaluated doing essays.

Using voltammetry curves, the performance of different unassailable electrodes was evaluated to compare them with the conventional lead electrode: platinum, graphite, and titanium with different surfaces: platinum, iridium oxide and ruthenium oxide. The cathode used in all cases was aluminum, with an effective area of $4 \mathrm{~cm}^{2}$, Figure 2.5. The anodes used are shown in Figures 2.3 and 2.4. Electrowinning was then conducted at 400,780 and $1000 \mathrm{~A} / \mathrm{m}^{2}$ to measure the operational parameters of the system.

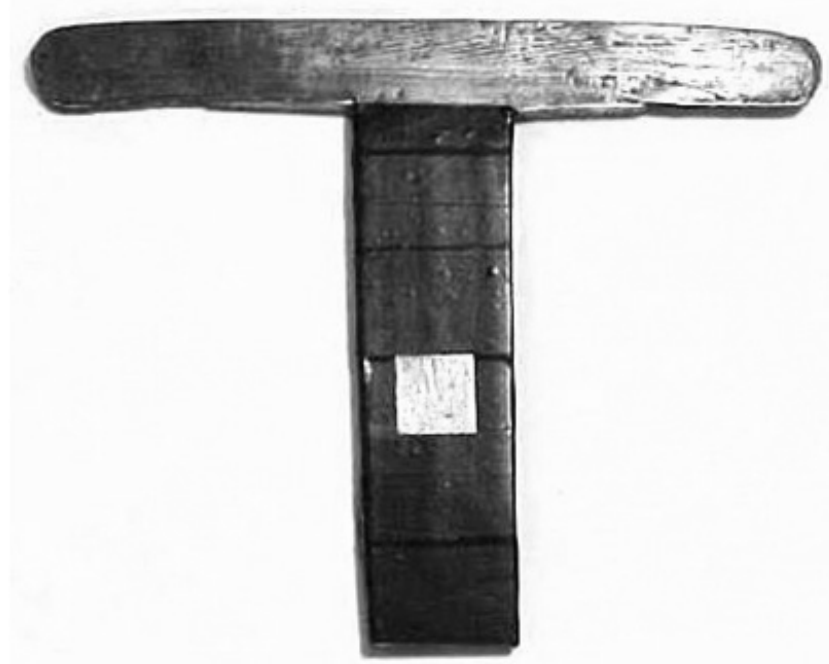

Figure 2.3.Lead anode used in voltammetry testing.

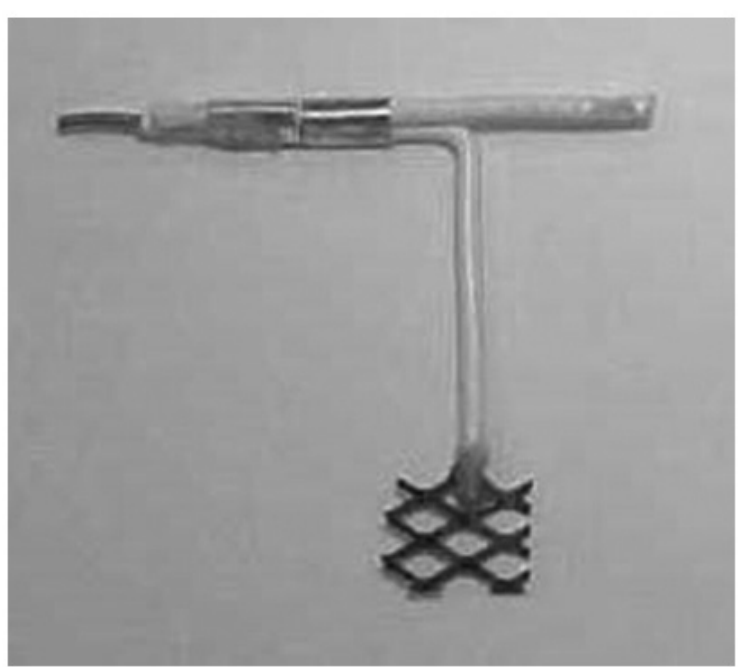

Figure 2.4.Iridium oxide anode used in voltammetry testing.

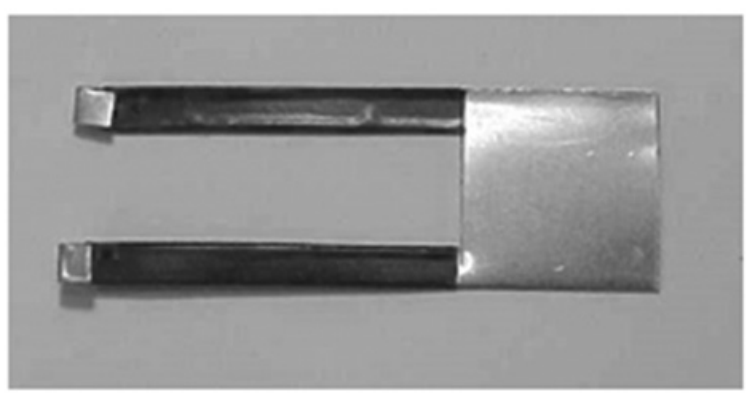

Figure 2.5.Aluminum cathode used for electrowinning tests.

\section{RESULTS AND DISCUSSION}

Figures 3.1 and 3.2 show linear voltammetry conducted in the mentioned working conditions in developing the experiment at different temperatures:

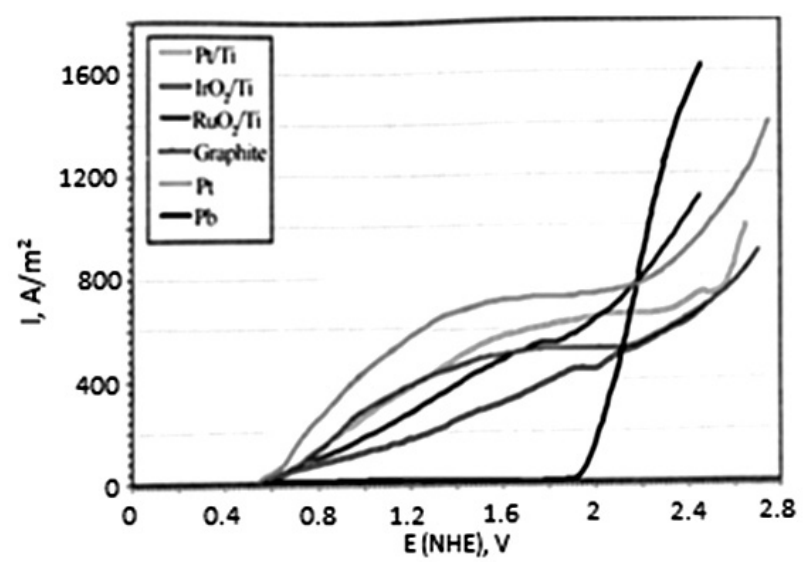

Figure 3.1.Linear voltammetry in different working electrodes, at $25^{\circ} \mathrm{C}$. 


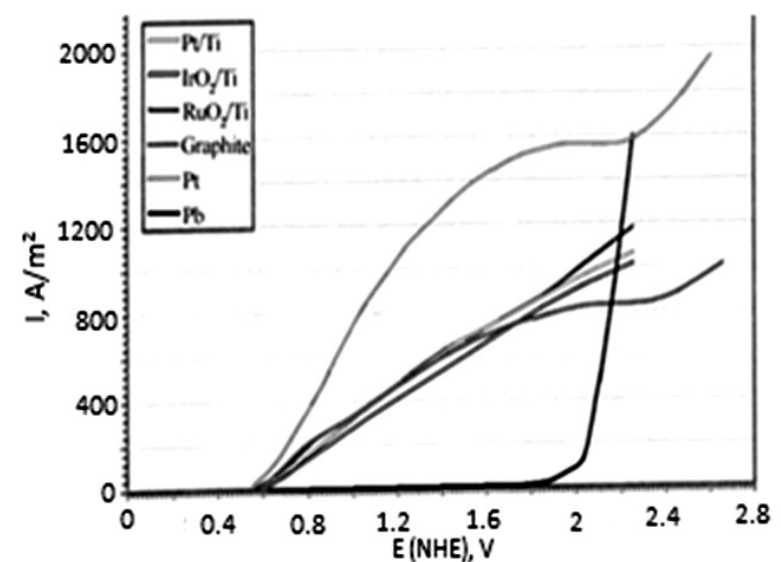

Figure 3.2.Linear voltammetry in different working electrodes, at $50^{\circ} \mathrm{C}$.

Figures 3.1 and 3.2, illustrate the importance of using the membrane and replacing the main anodic reaction of the oxidation of water for the oxidation of ferrous ion: by being able to separate the work environment, applying an overpotential is no longer required to maintain the surface stability of the lead dioxide over the conventional electrode in electro-winning in the work environment of sulfate. Moreover, the use of the oxidation reaction of ferrous ions decreases the energy difference between the main reactions, implying that the energy required to operate the system decreases, according to equation (1.2). Both effects, according to Figures 3.2 and 3.2, act in synergy and reduce energy consumption by approximately $1.4 \mathrm{~V}$.

Figure 3.3 shows how stirring influences of cells potential in the work cell:

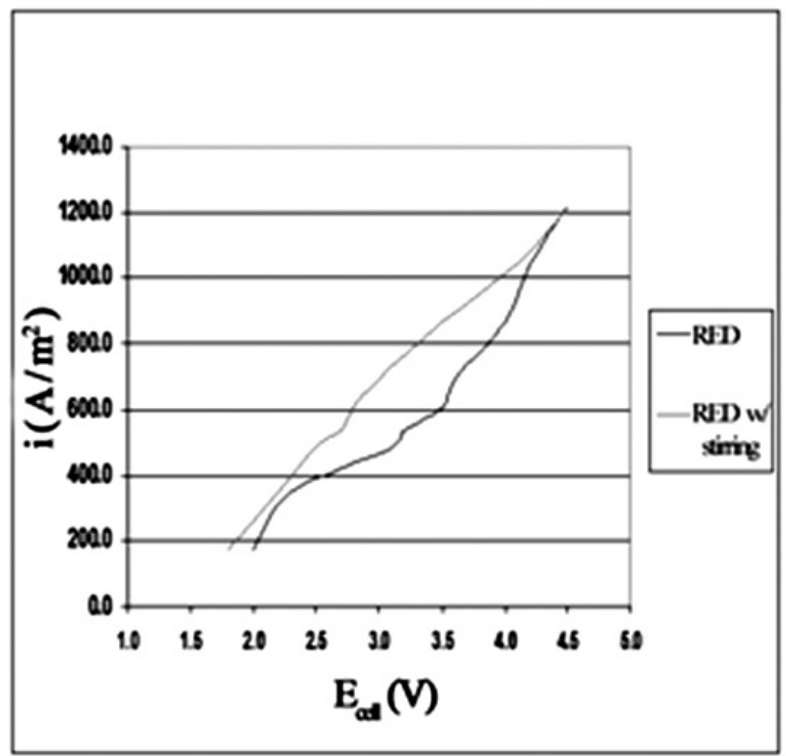

Figure 3.3. Influence of stirring in the cell potential.

Figure 3.3 shows that the total energy consumption decreases as stirring in the system increases. The influence will depend on the current density used. At low values of this parameter, the system operates on control by charge transfer, that is, the exchange of electrons in the metal-solution interface. Therefore, stirring scarcely contributes in the transport of ions. This trend is reversed as current density increases, first passing through a mixed type control and reaching a diffusional type control. This explains why stirring becomes important as current density rises. When very high values are reached, stirring loses importance due to the occurrence of parasitic reactions, such as oxygen bubbling in the anode and of hydrogen, in the cathode.

Figures 3.4 and 3.5 show the influence of current density on the $\mathrm{Zn}$ deposit.

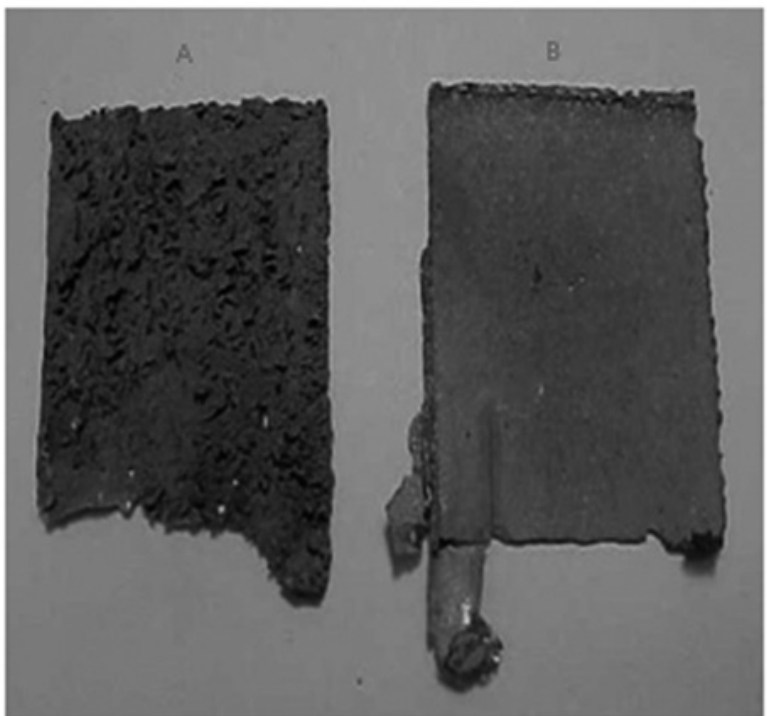

Figure 3.4. Zn cathodes obtained in the work system at (A) $1040 \mathrm{~A} / \mathrm{m}^{2} \mathrm{y}$ (B) $400 \mathrm{~A} / \mathrm{m}^{2}$.

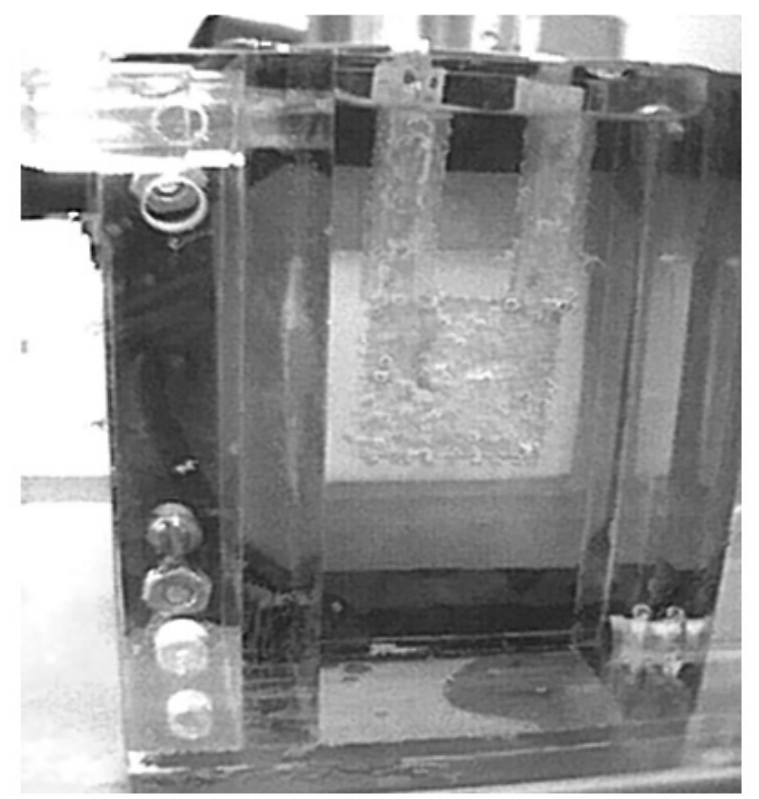

Figure 3.5. Hydrogen bubbling in $\mathrm{Zn}$ cathodes.

At high current density, the occurrence of parasitic hydrogen bubbling reaction is promoted, since according to the Evans diagram of Figure 3.6, this reaction always occurs in this system due to the use of an acid medium and the fact that its potential is located between the potentials of the 2 main reactions.

Another important effect that occurs in the operation of this system is the increase of conductivity of both electrolytic solutions, the anolyte and the catholyte. This is due to the behavior of ions in the presence of the electric field and the anode reaction: protons travel through the cationic membrane from the anolyte to the catholyte, while in the anolyte, the production of ferric ions increase the conductivity, since they have a smaller ionic radius compared to ferrous irons, thereby influencing the mobility of the ions within the medium. To corroborate this, ionic conductivities were measured with a conductivity meter, and the results are shown in Table 3.1: 


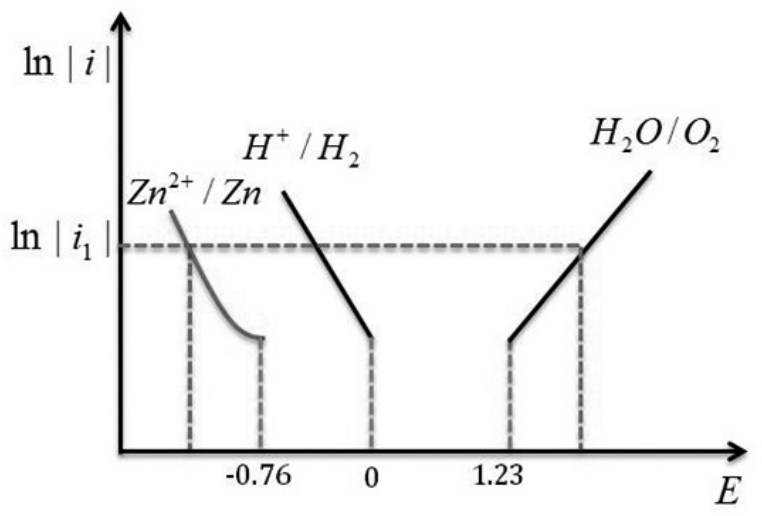

Figure 3.6.Evans Diagram of $\mathrm{Zn}$ electrowinning.

Table 3.1.Conductivities of the solutions.

\begin{tabular}{|c|c|c|}
\hline Sample & Start $(\mathrm{mS} / \mathrm{cm})$ & End $(\mathrm{mS} / \mathrm{cm})$ \\
\hline Anolyte & 355 & 365 \\
\hline Catholyte & 140 & 145 \\
\hline
\end{tabular}

Figure 3.7 shows temperature influences of cell potential in the work cell: For most electrochemical systems, temperature always has beneficial effects on all operating parameters. This is because they have high activation energy, which means they are sensitive to temperature changes.

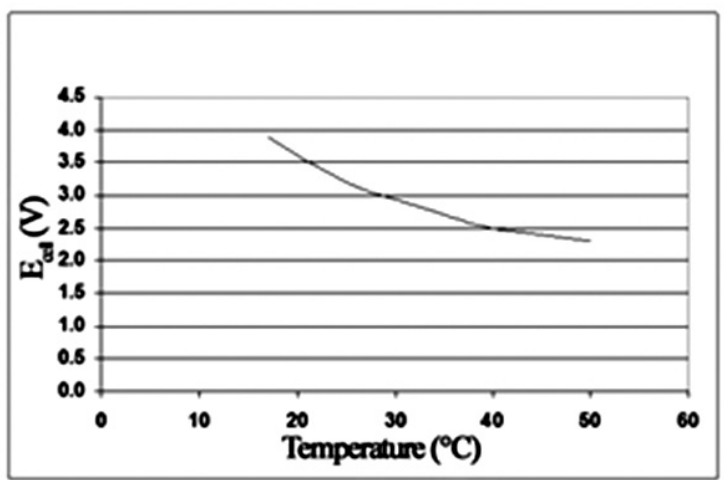

Figure 3.7. Cell potential v/s system temperature at current density of 780 $\mathrm{A} / \mathrm{m}^{2}$

All measured variables have an impact on the cell potential. Figure 3.8 shows the energy savings associated with the use of the work cell presented here. Although membranes generally have much lower ionic conductivity than the electrolyte, its use is justified because of it offers the possibility to change the work environments and uses other electrodes than lead.

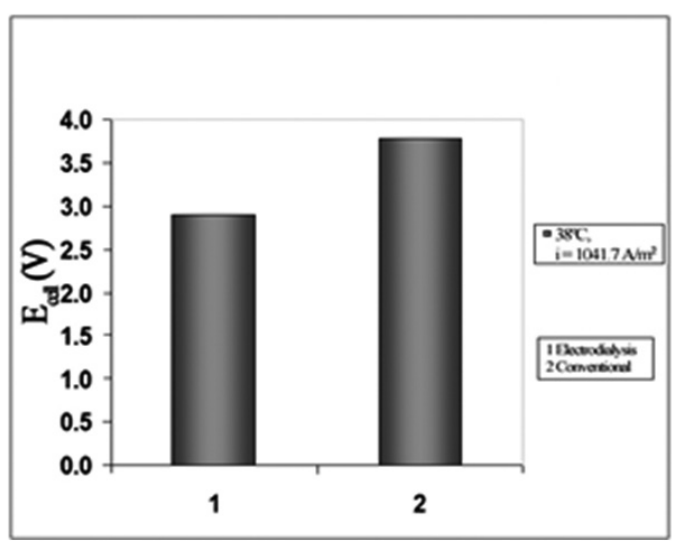

Figure 3.8.Comparison of Cells Potential in reactive electro-dialysis cell and conventional work cell.

\section{CONCLUSIONS}

Zinc electrowinning using reactive electrodialysis (RED) in an acid environment, and employing the $\mathrm{Fe}^{2+}$ to $\mathrm{Fe}^{3+}$ oxidation as the anodic reaction appears to be a real alternative zinc recovery. The RED process is very sensitive to stirring, so kinetics are initially under mixed control and mass transfer control (diffusion).

$\mathrm{Fe}^{2+}$ to $\mathrm{Fe}^{3+}$ is a fast anodic reaction, requiring low overpotentials compared to the $\mathrm{O}_{2}$ evolution reaction. As a result, the current intensity increases with an increase of applied potential with a tendency to a limiting current density of about $400 \mathrm{~A} / \mathrm{m}^{2}$

Electrolyte flow in this system must be sufficient to keep the cell agitation and to prevent the creation of concentration gradients in the $\mathrm{Fe}^{2+} / \mathrm{Fe}^{3+}$ anolyte.

The resistive terms of zinc electro-dialysis with the $\mathrm{Fe}^{2+} / \mathrm{Fe}^{3+}$ anolyte are all together less in magnitude than the resistive terms in conventional of zinc electrowinning.

By changing conventional anodic reaction of $\mathrm{O}_{2}$ evolution by the oxidation of $\mathrm{Fe}^{2+}$ to $\mathrm{Fe}^{3+}$, the problem of generation of acid mist is removed.

\section{ACKNOWLEDGEMENTS}

Support of this work by DICYT of the Universidad de Santiago de Chile is gratefully acknowledged.

\section{REFERENCES}

1. Process and Technology of Zinc Refinery Process, http://www.xmetech. com/technology/zincRefining.asp?loc=Leaching

2. J.O'M. Bockris, A.K.N. Reddy, Modern electrochemistry,Plenum Press, New York, (1977).

3. A.K. Biswas, W.G. Davenport,Extractive Metallurgy of Copper, 3th edition, Pergamon Press, Oxford, (1994).

4. L. Cifuentes, E. Astete, G. Crisóstomo, J. Simpson, G. Cifuentes, M. Pilleux, Corrosion Engineering, Science and Technology, 40, 4, 321-327 (2005).

5. G. Cifuentes, J. Simpson and H. Godoy, Modelamiento de la conductividad en electrolitos $\mathrm{H}_{2} \mathrm{SO}$ - $\mathrm{Cu}$, Editorial Académica Española, Madrid, (2011).

6. G. Cifuentes, J. Simpson, F. Lobos, L. Briones and A. Morales,J. Chil. Chem. Soc., 54, 4, (2009).

7. J.M. Casas, G. Crisóstomo, L. Cifuentes, Hydrometallurgy, 80, 4, 254, (2005).

8. L. Cifuentes, G. Crisóstomo, J.P. Ibáñez, J.M. Casas, F. Álvarez, G. Cifuentes, J. ofMembrane Sc., 207, 1, (2002).

9. L.Cifuentes,R.Glasner, J.M. Casas, Chem. Eng. Sci., 59, 5, 1087,(2004).

10. L. Cifuentes, C. Mondaca, J.M. Casas, Minerals Engineering, 17, 803, (2004).

11. A.M. Bernardes, M.A.Siqueira, and J. Zoppas,Electrodialysis and Water Reuse: Novel Approaches - Topics in Mining, Metallurgy and Materials Engineering, First Edition, Springer, Berlin-Heidelberg, (2013).

12. L. Cifuentes, R. Ortiz, J.M. Casas, AIChE J.51, 8, 2273, (2005).

13. L. Cifuentes, J. Simpson, Chem. Eng. Sci., 60, 17, 4915, (2005).

14. J. Newman inAdvances in Electrochemistry and Electrochemical Engineering, C. W. Tobias ed., New York, USA, 87, (1967). 